\title{
Being high is better: effects of elevation and habitat on arctic ground squirrel demography
}

\author{
Elizabeth A. Gillis, David S. Hik, Rudy Boonstra, Tim J. Karels and Charles J. Krebs
}

Gillis, E. A., Hik, D. S., Boonstra, R., Karels, T. J. and Krebs, C. J. 2005. Being high is better: effects of elevation and habitat on arctic ground squirrel demography. - Oikos 108: $231-240$.

\begin{abstract}
We investigated the effect of local environment on the demography and population dynamics of arctic ground squirrels (Spermophilus parryii plesius) by comparing reproduction, survival, and population trends of squirrels living in low elevation boreal forest and high elevation alpine tundra sites in southwestern Yukon Territory, Canada. Contrary to the trend for most birds and mammals, reproduction was significantly lower at the lower elevation and females living at higher elevation did not delay the age at which they first reproduced. Even though survival in the boreal forest was lower in summer than in the alpine, it was higher over winter so annual adult female survival was similar between sites.

Sensitivity analysis of model parameters revealed that in the forest, population growth rate $(\lambda)$ was most sensitive to small changes in adult active season survival whereas for the alpine population, $\lambda$ was most sensitive to changes in juvenile winter survival. In their respective habitats, these parameters also showed high year to year variation and thus contributed greatly to the population trends observed. Even though ground squirrels persisted in the boreal forest, the measured demographic rates indicate the forest was sink habitat $(\lambda<1)$ and may have relied on nearby grassy meadows for immigrants. In contrast, the alpine habitat maintained a ground squirrel population in the absence of immigration $(\lambda=1)$.

The variation in demographic rates between ground squirrels living at high and low elevation may arise from phenotypic responses of squirrels to different habitat structure. Arctic ground squirrels rely on sight to detect predators from a safe distance, and the boreal forest, with its lower visibility and higher predator density, appears to be suboptimal habitat.
\end{abstract}

E. A. Gillis and C. J. Krebs, Dept of Zoology, Univ. of British Columbia, 6270 University Boulevard, Vancouver, British Columbia, Canada V6T 1Z4 (gillis@zoology.ubc.ca). - D. S. Hik, Dept of Biological Sciences, Univ. of Edmonton, Alberta, Canada T6G 2E9. - R. Boonstra and T. J. Karels, Div. of Life Sciences, Univ. of Toronto at Scarborough, 1265 Military Trail, Scarborough, Ontario, Canada MIC 1 A4.

Geographic variation in population demography can greatly impact regional population dynamics of animals by facilitating source-sink dynamics and site dependent population regulation (Pulliam and Danielson 1991, Rodenhouse et al. 1997, Sutherland et al. 2002). Differences in demographic rates among populations can also lead to geographic variation in population dynamics if yearly changes in survival and reproduction rates differ among populations (Kreuzer and Huntly 2003). The degree of concordance of population dynamics over large spatial scales will therefore be a balance of unique local environments (abiotic and biotic) 
that will serve to differentiate populations, and shared regional factors that will serve to synchronize population dynamics.

Elevation gradients provide unique opportunities to study intraspecific variability in population demography and dynamics because they provide a wide range of environmental variability over a small spatial scale. During the summer in temperate regions and all year in tropical regions, temperature drops, on average, $6^{\circ} \mathrm{C}$ for every $1000 \mathrm{~m}$ increase in elevation, so a $1000 \mathrm{~m}$ change in elevation provides a climatic gradient equivalent to a $15^{\circ}$ change in latitude (Körner 1999). Because the environmental cline is so strong, populations of elevation generalist species living at different elevations will experience drastically different local conditions and may have different demographic rates. In general, populations of birds and mammals living at lower elevation have lower adult survival, longer breeding seasons, higher reproductive output per season, and younger ages of first reproduction than populations of the same species at higher elevations (Dunmire 1960, Spencer and Steinhoff 1968, Bronson 1979, Millar and Innes 1985, Zammuto and Millar 1985, Dobson and Murie 1987, Sorci et al. 1996, Ferguson and McLoughlin 2000, Badyaev and Ghalambor 2001, Bears et al. 2003). These differences facilitate tests of life history theory (Zammuto and Millar 1985, Stearns 1992, Sorci et al. 1996, Badyaev and Ghalambor 2001).

In this study, we use elevation to provide two contrasting local environments over a small spatial scale. Our objectives were to compare arctic ground squirrel demography and population dynamics at a low elevation boreal forest site $(900 \mathrm{~m})$ to a high elevation alpine site $(1700-1900 \mathrm{~m})$. We tested 3 predictions, based on trends observed in other herbivorous small mammals and consistent with life history theory, that females living at higher elevation should: (1) delay the age at which they first breed, (2) have higher survival, and (3) have lower per capita seasonal reproductive output than those living at lower elevation. To assess the sensitivity and elasticity of population growth rate to the various demographic parameters, we incorporated survival and reproductive rates for each population into a demographic model.

\section{Methods}

\section{The study species}

Arctic ground squirrels are burrowing, herbivorous small mammals (ca $500 \mathrm{~g}$ ) found throughout northern North America. In most of their range, they inhabit arctic and alpine tundra, but in the southern portion of their distribution they also inhabit boreal forest (Nadler and Hoffmann 1977). Arctic ground squirrels hibernate individually for eight months of the year, with little spatial or temporal variation in the dates of emergence from and immergence into hibernation, and mate as soon as females emerge from hibernation in May (Lacey et al. 1997, Buck and Barnes 1999). Females produce only one litter of young each year and altricial young are born 25 days after mating (Lacey et al. 1997). Young develop in underground nests for an additional 28 days, are weaned within a week of emerging from their natal nests, and are reproductively mature as yearlings (Carl 1971, Lacey et al. 1997). Adult and juvenile females are philopatric, but $57-100 \%$ of juvenile males disperse prior to their first winter (Byrom and Krebs 1999) and 41-68\% of reproductively mature males disperse between breeding seasons (Lacey 1991).

\section{Description of study site}

We studied ground squirrels at two sites, located approximately $35 \mathrm{~km}$ apart, that differed in elevation, climatic conditions, herbivore and predator communities (Table 1) as well as vegetation. The lower elevation boreal forest was dominated by white spruce forests $(43 \%)$ and willow shrub thickets $(45 \%)$ with occasional grassy meadows $(8 \%)$ and aspen poplar stands (5\%; Krebs et al. 2001). The higher elevation alpine site consisted of unvegetated boulderfields (36\%), patches of moss, lichens, and bare ground (37\%), and vascular plants (Salix, Carex, Dryas, Cassiope spp. 37\%; Hik et al. 2001, McIntire and Hik 2002). Although the species composition of available forage differed between sites, the amount of forage available to ground squirrels during the peak of the growing season was similar between sites (Hik et al. 2001).

In the boreal forest, ground squirrels were studied on two to four 10 ha grids spaced $1.5 \mathrm{~km}$ to $>15 \mathrm{~km}$ apart (Hubbs and Boonstra 1997, Krebs et al. 2001). At the alpine site, ground squirrels were studied on two 12 ha grids located $400 \mathrm{~m}$ apart (grid size in $1998=3 \mathrm{ha}$ ). Both the lower elevation boreal forest and the higher elevation alpine site were part of long term ecosystem projects, the Kluane Boreal Forest Ecosystem Project and Monitoring Program (Krebs et al. 2001, C. Krebs and R. Boonstra, unpubl.), and the Kluane Alpine Ecosystem Project (D. Hik, unpubl.). Data were collected from 1990 to 2003 at the boreal forest site and 1998 to 2003 at the alpine site. Not all data were available from both sites for all years, so the number of years included in each analysis varied.

\section{Population trends}

Squirrel censuses were conducted from 1998 to 2003 on two grids at both the boreal forest and alpine sites. Each mark-recapture census consisted of two to six 
Table 1. Comparison of abiotic and biotic conditions at the low elevation boreal forest study site and the higher elevation alpine study site. Temperature inversions are common during the winter and are responsible for the warmer temperature at the alpine site relative to the boreal forest site in January. Data are from Krebs et al. (2001), Hik et al. (2001) and McIntire and Hik (2002) except for temperature data (Environment Canada, D. Hik, unpubl.).

\begin{tabular}{|c|c|c|}
\hline & Forest site & Alpine site \\
\hline Location & $60^{\circ} 57^{\prime} \mathrm{N}, 138^{\circ} 12^{\prime} \mathrm{W}$ & $61^{\circ} 20^{\prime} \mathrm{N}, 138^{\circ} 25^{\prime} \mathrm{W}$ \\
\hline Elevation $(\mathrm{m}$; tree line $=1200 \mathrm{~m})$ & 900 & $1700-1900$ \\
\hline Mean January temperature $\left({ }^{\circ} \mathrm{C}\right)$ & -22 & -13 \\
\hline Mean July temperature $\left({ }^{\circ} \mathrm{C}\right)$ & 11 & 7 \\
\hline Mean annual precipitation (mm) & 286 & 250 \\
\hline Snow free period & early May to October & mid June to late August \\
\hline Dominant herbivores & $\begin{array}{l}\text { snowshoe hare, red squirrel, arctic } \\
\text { ground squirrel, moose, mice and voles } \\
\text { (Peromyscus, Clethrionomys, and } \\
\text { Microtus spp.) }\end{array}$ & $\begin{array}{l}\text { hoary marmots, arctic ground } \\
\text { squirrel, collared pika, rock } \\
\text { ptarmigan, brown lemmings, } \\
\text { voles (Clethrionomys and } \\
\text { Microtus spp.) }\end{array}$ \\
\hline Ground squirrel predators & coyote, lynx, great horned owl, goshawk & red fox, golden eagle, grizzly \\
\hline $\begin{array}{l}\text { Number of predators sighted per } 100 \\
\text { field hours (1995 and 1996) }\end{array}$ & 0.76 & 0.24 \\
\hline
\end{tabular}

consecutive days of trapping in late July. In 1998, we placed traps at burrows at the alpine site. In all other years, and at the boreal forest site, we placed traps at permanent grid stakes systematically located within the trapping area $(50 \mathrm{~m}$ grid system in the alpine, $30 \mathrm{~m}$ grid system in forest with traps at alternate grid stakes). We tagged squirrels with uniquely numbered metal eartags when first captured, and on this and subsequent captures, we recorded identity, age (adult or juvenile), sex, reproductive condition, weight $( \pm 5 \mathrm{~g})$, and zygomatic arch breadth $( \pm 0.5 \mathrm{~mm})$.

We estimated adult and total population sizes and $95 \%$ confidence limits using the jackknife estimator in the program Capture (Otis et al. 1978, Boulanger and Krebs 1994). To obtain density, we divided the population estimate by the effective trapping area which included an "edge effect" area to account for animals caught on the grid that did not live entirely on the grid (Bondrup-Nielsen 1983). The edge effect distance (the average distance moved by individuals caught more than once during the census; $50 \mathrm{~m}$ at the forest site and $80 \mathrm{~m}$ at the alpine site) was added to all sides of the actual trapping grid to establish the effective trapping area. Separate estimates were obtained for two grids at each site, and we report the mean for each site.

Annual finite rate of adult population increase $(\lambda)$ in each habitat was calculated for each year (Eq. 2). Maximum and minimum rates of increase were determined using the upper and lower 95\% confidence limits associated with the mean density for each year.

\section{Survival}

Minimum annual survival (late summer to late summer) of juvenile and adult females was estimated from 1992 to 2003 at the forest site and from 1998 to 2003 at the alpine site. Minimum survival was the proportion of residents (individuals captured more than once during the census) we captured during one census that we captured during the following year's census. We estimated survival for females only because we could not distinguish disappearance from dispersal and death using trapping methods, and juvenile and adult males disperse.

For 1991 to 2003 at the forest site and 2000 to 2002 at the alpine site, we subdivided annual survival into active season (summer) and winter survival. Active season survival was the proportion of females caught before May 31 that were caught after July 15 th of the same year (July 1st in 2002). Adult females enter into hibernation starting in late July at both elevations (McLean and Towns 1981, E. Gillis unpubl.) so most females that disappeared after July 15 th probably entered hibernation as opposed to died. For the boreal forest population, winter survival estimates prior to 1998 have been published (Karels 2000, Karels et al. 2000). For all other years and for the alpine population, we calculated winter survival in the same manner (the proportion of females caught during the last week of July or August that were caught in a subsequent year). We combined data from adults and juveniles for winter survival estimates in the boreal forest because survival did not differ statistically between juveniles and adults (Karels et al. 2000) but calculated adult and juvenile winter survival separately for the alpine site.

\section{Reproduction}

Lactation rates, weaning success, and reproductive output for the boreal forest population have been published for 1991-1997 (Hubbs and Boonstra 1997, Karels 2000, Karels et al. 2000). In the alpine, we trapped ground squirrels throughout the active season from 2000 to 2002 
to monitor reproduction using the same methods as in the boreal forest. Lactation rate was the percentage of females trapped during the lactation period that had large nipples from which milk could be expressed. Between onset of lactation and juvenile emergence, we radio-collared lactating females with $1.5 \mathrm{~g}$ transmitters (Model PD-2C, Holohil Systems Ltd., Carp, Ontario, Canada) and located their nest burrows. We determined litter size by observing these burrows and trapping juveniles once they emerged. Weaning success was the percentage of females that lactated who had at least one juvenile emerge from their natal nests (i.e. the weaning success of females that gave birth). We calculated reproductive output (number of juveniles $\times$ female $^{-1} \times$ year $^{-1}$ ) for each year by multiplying yearly lactation rate, weaning success, and mean litter size. To compare reproductive output between females living in the boreal forest and alpine for concurrent years (1998 to 2002), we used a surrogate of reproductive output-the ratio of juveniles to adults trapped during the census. To see if a fewer proportion of yearlings bred at the higher elevation, we classified all known yearlings caught during the two week period when most females lactated (June 1-14, 1993 to 1997 at the forest site, June 8-22, 2000 to 2002 at the alpine site) as either lactating or not lactating.

\section{Demographic model}

For each site, we incorporated the measured demographic rates into a model that predicted the number of females in one spring $\left(\mathrm{n}_{\mathrm{t}+1}\right)$ from the number of females alive the previous spring $\left(\mathrm{n}_{\mathrm{t}}\right)$. We assumed an equal sex ratio at birth (Green 1977) and that females had to live half of the active season ( 8 weeks) in order to successfully wean young, so:

$$
\begin{aligned}
\mathrm{n}_{(\mathrm{t}+1)}= & \left(\mathrm{n}_{\mathrm{t}} \times \mathrm{LA}_{\mathrm{act}} \times \mathrm{LA}_{\mathrm{ow}}\right) \\
& +\left(\mathrm{n}_{\mathrm{t}} \mathrm{LA}_{\mathrm{act}}^{1 / 2} \times \mathrm{m} / 2 \times \mathrm{LJ}_{\mathrm{act}} \times \mathrm{LJ}_{\mathrm{ow}}\right)
\end{aligned}
$$

where $L_{A} A_{a c t}=$ adult female active season survival, $\mathrm{LA}_{\mathrm{ow}}=$ adult female winter survival, $\mathrm{m}=$ reproductive output (young weaned per female), $\mathrm{LJ}_{\mathrm{act}}=$ juvenile female active season survival, and $\mathrm{LJ}_{\mathrm{ow}}=$ juvenile female winter survival.

The per capita growth rate of the female population $(\lambda)$ was:

$\lambda=\mathrm{n}_{(\mathrm{t}+1)} / \mathrm{n}_{\mathrm{t}}$

Female arctic ground squirrels are highly trappable (mean minimum trappability $=81 \%$; Hubbs and Boonstra 1997), and active season minimum survival estimates based on trapping averaged only $10 \%$ less than active season survival estimates from concurrent telemetry studies (this study compared with Hubbs and Boonstra 1997, Byrom et al. 2000). Since telemetry studies were not done in all years, we multiplied mean minimum survival estimates based on trapping by 1.1 to parameterize the model.

Juvenile active season survival in this study was not directly measured, but a previous study reported 28 day survival rates for juvenile females that averaged $87 \%$ of adult 28-day survival rates (Byrom et al. 2000). We assumed adult females were active for 16 weeks and juvenile females were active for 10 weeks prior to hibernation, so:

$$
\mathrm{LJ}_{\mathrm{act}}=\left(\mathrm{LA}_{\mathrm{act}}^{1 / 4} \times 0.87\right)^{2.5}
$$

(Eq. 3 after Krebs 1999, Eq. 14.2) Sensitivity and elasticity analyses (Caswell 2001) were conducted on the models using Excel add in PopTools version 2.4 (Hood 2002). The elasticity of each parameter was then multiplied by its coefficient of variation $(\mathrm{CV})$. The resulting value (the actual elasticity [AE] coefficient) combines the proportional sensitivity of the growth rate of the parameter with how much the parameter actually varies, and is measured in units of standard deviation of the parameter (Haydon et al. 1999). CV values for the boreal forest were based on seven to 12 years of data while the alpine CV values were based on only three years, so we evaluated the robustness of each parameter's AE coefficient ranking. For each parameter, the $\mathrm{CV}$ for each three-year period $\left(\mathrm{CV}_{3}\right)$ in the boreal forest data set was calculated and the mean $\mathrm{CV}_{3}$ and measured standard deviation was used in a Monte Carlo simulation (500 randomizations) to determine the degree to which each parameter's AE coefficient ranking was dependent on the CV values used.

\section{Results}

\section{Population trends}

Total ground squirrel density in late summer tended to be $30-70 \%$ higher at the alpine site than at the boreal forest site (Fig. 1). This difference was due to a larger number of juveniles at the alpine site, as adult density at the two sites was similar in most years (Fig. 2). At both study sites, total and adult ground squirrel density declined between 1998 and 1999. In the forest, total and adult squirrel density continued to decline until 2000 after which densities remained stable. In the alpine, adult squirrel density remained stable between 1999 and 2002 even though total squirrel density increased during this time. In 1998 and 1999, the maximum and minimum possible yearly finite population growth rates $(\lambda)$ for adults, based on the error associated with the population estimates of adults, did not overlap between sites (Fig. 2). However, after 1999, population growth rate showed similar trends between the two areas. 


\section{Survival}

Seasonal survival of adults differed significantly between sites; adult females in the forest had 28\% higher winter survival but $38 \%$ lower summer survival than females in the alpine (Fig. 3). Although mean winter survival was higher at the boreal forest site for juveniles as well $(68 \%$ vs $55 \%$ ), the difference was not statistically significant (Fig. 3). The differences in seasonal survival between the sites cancelled each other out and minimum annual survival of females did not differ between the forest and the alpine sites (Fig. 3).

\section{Reproduction}

Juveniles were first observed June $19 \pm 2.6$ (mean \pm 1 SE, $\mathrm{n}=7$ years) at the boreal forest site, one week earlier than at the alpine site on June $25 \pm 1.2$ days $(\mathrm{n}=3)$. The proportion of yearlings that lactated in the forest $(76.2 \%, \mathrm{n}=21)$ and in the alpine $(88.2 \%, \mathrm{n}=17)$ was similar (data from all years combined, likelihood ratio $\chi^{2}=0.94, \mathrm{df}=1, \mathrm{p}=0.33$ ), indicating females at high elevation did not delay the age at which they first bred. However, on average females in the boreal forest produced only half the number of young per year as females in the alpine because in the forest, significantly fewer females lactated and there was a trend towards smaller litter sizes (Fig. 4). A second measure of reproductive output, the ratio of juveniles to adults trapped during the census, obtained for concurrent years at the two sites reflected the lower reproductive output at the forest site (Fig. 2, log-linear analysis, year: Wald $\chi^{2}=25.1, \mathrm{df}=5, \mathrm{p}=0.001$, site: Wald $\chi^{2}=5.6$, $\mathrm{df}=1, \mathrm{p}=0.02$ ).

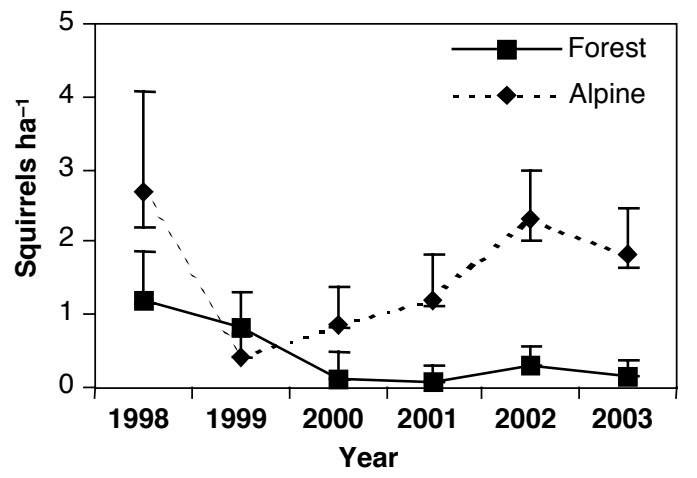

Fig. 1. Differences in arctic ground squirrel densities at a low elevation boreal forest site and a high elevation alpine site, 1998-2003. Censuses were conducted on 2 grids at each site in late July or early August of each year. Error bars are the mean upper and lower $95 \% \mathrm{cl}$.

\section{Demographic model}

Although the arctic ground squirrel population in the alpine was stable $(\lambda=1)$, the boreal forest population could not maintain itself in the absence of immigration $(\lambda<1$, Table 2). Sensitivity analyses indicated that in the forest, population growth rate was sensitive to small changes in adult active season survival while in the alpine, population growth rate was sensitive to small changes in adult and juvenile winter survival (Table 2). Growth rate of neither population was sensitive to small changes in reproductive output. In terms of the proportional sensitivity of the growth rate to proportional changes in parameter values (elasticity), growth rate was most sensitive to changes in adult active season survival in both populations (Table 2).

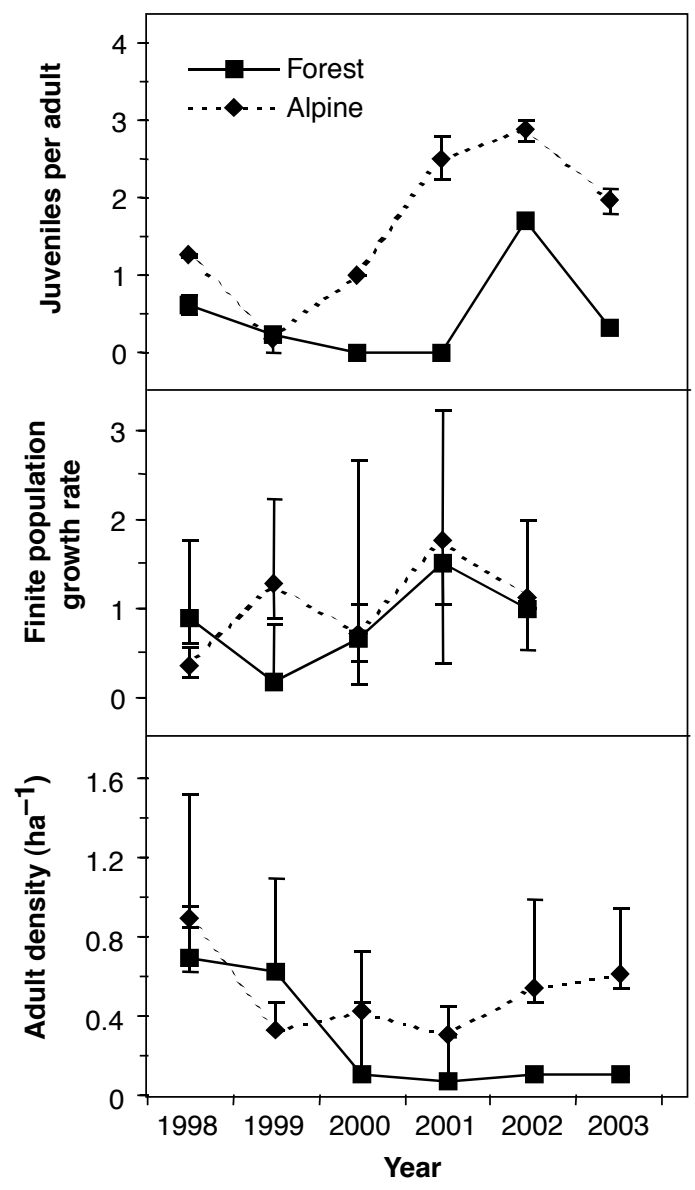

Fig. 2. Trends in arctic ground squirrel dynamics at a low elevation boreal forest site and a high elevation alpine site, 1998-2003. Censuses were conducted on 2 grids at each site in late July or early August of each year. Adult density error bars are the mean upper and lower $95 \%$ confidence limits, yearly finite population growth rate error bars represent the minimum and maximum values based on the $95 \%$ confidence limits associated with the density estimates for each habitat, and the number of juveniles per adult is reported as mean $\pm 1 \mathrm{SE}$. 


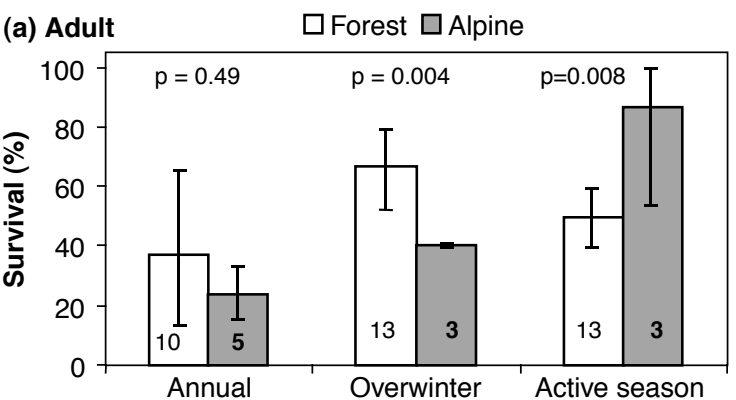

(b) Juvenile

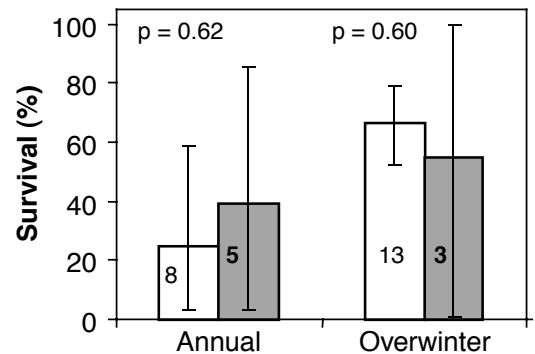

Fig. 3. Minimum survival rates of adult and juvenile female arctic ground squirrels at a low elevation boreal forest site and a high elevation alpine site. Survival was estimated for each of $n$ years (indicated on bars) and the yearly rates were averaged. The error bars indicate $95 \% \mathrm{cl}$. Means were compared using ttests, or if variances were not equal (Levene's test $\alpha=0.05$ ) a Welch's F-test (Sall et al. 2001), of arcsine transformed data (Krebs 1999).

In the forest population, reproduction and active season survival varied greatly from year to year, whereas in the alpine population juvenile winter survival was highly variable (Table 2 ). As a result, in the boreal forest, the $\mathrm{AE}$ coefficient (elasticity $\times$ coefficient of variation) for adult active season survival was $50 \%$ higher than the next highest AE coefficient (adult winter survival, Table 2). In contrast, in the alpine the juvenile winter survival $\mathrm{AE}$ coefficient was twice as high as the next highest AE coefficient (reproductive output, Table 2). The boreal forest results fluctuated when the coefficient of variation used was based on a random set of 3 years of data (the same number of years available for the alpine population) as opposed to calculated from all years available, but adult survival consistently ranked higher than juvenile survival (Table 3).

\section{Discussion}

Although the low elevation boreal forest and higher elevation alpine sites were only $35 \mathrm{~km}$ apart, arctic ground squirrels living at the two sites differed in a number of ways. Reproductive output at the higher elevation alpine site was greater than at the lower elevation site (Fig. 4), contrary to the trend for most birds and mammals. Annual female survival was similar at the study sites but seasonal survival between sites differed. Specifically, adult female survival in the boreal forest was lower in the summer but higher in the winter than in the alpine (Fig. 3).

This study was conducted at two sites, one at each elevation, and therefore may simply represent site differences as opposed to differences associated with elevation. Several pieces of evidence indicate this is not the case. Although the two grids studied at the alpine site were $<500 \mathrm{~m}$ apart, the two main study grids at the boreal forest site were $>15 \mathrm{~km}$ apart, and would account for spatial variability in this habitat. Addition-

Table 2. Sensitivity and elasticity of arctic ground squirrel population growth rate $(\lambda)$ to demographic parameters at a low elevation forest site (a) and high elevation alpine site (b). CV is the measured coefficient of variation of a parameter and was multiplied by the elasticity to obtain the actual elasticity (AE). The AE coefficient is measured in units of the standard deviations of the parameter. Thus, if reproductive output in the alpine was increased by $10 \%$ of its observed standard deviation, $\lambda$ would increase by $0.10 \times 0.26 \times 100=2.6 \%$, from 1.0 to 1.03 .

\begin{tabular}{|c|c|c|c|c|c|}
\hline Parameter & Value & Sensitivity & Elasticity $\left(\mathrm{e}_{\mathrm{i}}\right)$ & $\mathrm{CV}_{\mathrm{i}}$ & $\mathrm{AE}$ \\
\hline \multicolumn{6}{|l|}{ (a) Low elevation forest site } \\
\hline Reproductive output (m) & 1.5 & 0.12 & 0.33 & 47.3 & 0.15 \\
\hline Juvenile active season survival $\left(\mathrm{LJ}_{\mathrm{act}}\right)$ & 0.480 & 0.38 & 0.33 & 34.8 & 0.11 \\
\hline Juvenile winter survival ( $\mathrm{LJ}_{\text {ow }}$ ) & 0.700 & 0.26 & 0.33 & 31.8 & 0.10 \\
\hline Adult active season survival ( LA $\left._{\text {act }}\right)$ & 0.547 & 0.87 & 0.84 & 34.8 & 0.29 \\
\hline Adult winter survival $\left(\mathrm{LA}_{\mathrm{ow}}\right)$ & 0.700 & 0.54 & 0.67 & 31.8 & 0.21 \\
\hline Growth rate ( $\lambda$ from Eq. 1 and 2$)$ & & & & & \\
\hline$\lambda 95 \%$ confidence limits* & $0.3-0.9$ & & & & \\
\hline \multicolumn{6}{|l|}{ (b) High elevation alpine site } \\
\hline Reproductive output (m) & 3.0 & 0.20 & 0.59 & 44.8 & 0.26 \\
\hline Juvenile active season survival $\left(\mathrm{LJ}_{\mathrm{act}}\right)$ & 0.678 & 0.87 & 0.59 & 21.3 & 0.12 \\
\hline Juvenile winter survival $\left(\mathrm{LJ}_{\mathrm{ow}}\right)$ & 0.604 & 0.99 & 0.59 & 98.1 & 0.57 \\
\hline Adult active season survival ( $\left.\mathrm{LA}_{\mathrm{act}}\right)$ & 0.950 & 0.76 & 0.71 & 21.3 & 0.15 \\
\hline Adult winter survival (LA $\left.{ }_{\mathrm{ow}}\right)$ & 0.444 & 0.95 & 0.41 & 1.7 & 0.01 \\
\hline Growth rate ( $\lambda$ from Eq. 1 and 2$)$ & 1.0 & & & & \\
\hline$\lambda 95 \%$ confidence limits* & $0.6-1.7$ & & & & \\
\hline
\end{tabular}

*Based on Monte Carlo simulation (500 replications). 


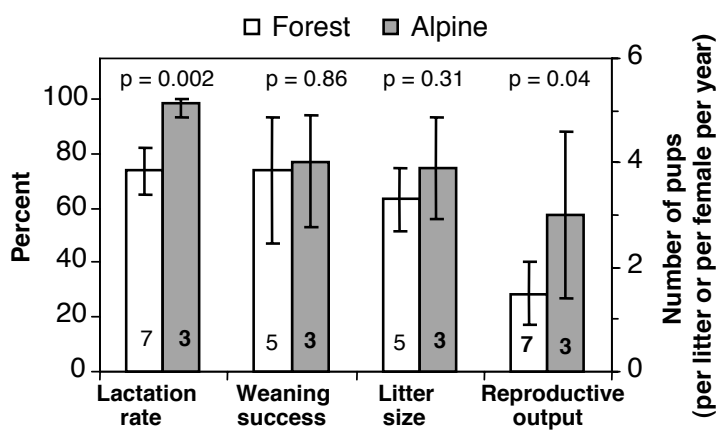

Fig. 4. Reproductive traits of female arctic ground squirrels living at a low elevation boreal forest site and high elevation alpine site. Lactation rate was the percent of females that lactated and the weaning success was the percent of lactating females that successfully weaned a litter (left y-axis). Litter size was the number of pups weaned per litter and reproductive output was the mean number of pups weaned per female per year (right y-axis). Reproductive values were obtained for each of $\mathrm{n}$ years (indicated on bars) and these yearly values were averaged. Error bars indicate $95 \% \mathrm{cl}$. Means were compared using t-tests, or in the case of unequal variances (Levene's test $\alpha=0.05$ ) a Welch's F-test (Sall et al. 2001). Proportional data were arcsine transformed prior to analysis (Krebs 1999).

ally, many of the factors affecting the boreal forest population appear to be related to changes in predation pressure (below), which in turn is influenced by snowshoe hare and alternate prey abundance, a characteristic common across the whole boreal forest. Importantly the main results from this study are consistent with previous studies, as will be discussed.

The main limitation of the current study is that data were collected for fewer years in the alpine than in the boreal forest and years of concurrent study (1998 to 2003) were hindered by small sample sizes in the boreal forest. In many instances, year effects could not be statistically evaluated. However, the data set for the boreal forest spanned many years and captured the range of natural variation, minimizing this problem. In addition, when seasonal survival analysis were restricted to years in which data was available from both study sites, although not statistically significant, trends remained the same. For active season survival, survival in the boreal forest was lower than in the alpine for all three years of concurrent study, and for both juvenile and adult winter survival, survival was higher in the boreal forest for 2 of the 3 years and only marginally lower in the third.

\section{Population trends}

Changes in numbers of adults at both sites followed similar trends from 1998 to 2003 (Fig. 2), but differences in seasonal survival and reproduction and results from the model indicate the demographic factors underlying these changes may have differed between sites. For the boreal forest population, adult active season survival had the highest AE coefficient (sensitivity $\times$ coefficient of variation), indicating this parameter could contribute greatly to the changes in numbers observed. For the alpine population, changes in juvenile winter survival may have played a dominant role in creating the observed trends in population numbers.

Based on the model results, the alpine population was stable $(\lambda=1)$ whereas the boreal forest may be a sink population $(\lambda<1$, but see Watkinson and Sutherland 1995). Indeed, from 2000 to 2002 , no ground squirrels were trapped on one of the boreal forest grids, indicating a local extinction event in the forest. A single juvenile female was trapped on the grid in 2003. Immigrants most likely come from large open meadows interspersed within the forest, as populations in the meadows have higher local density and reproductive output than populations in the forest (Lacey et al. 1997 compared with data in Karels et al. 2000, Krebs et al. 2001). The level of immigration required, whether or not populations in meadows could supply the required number, and the potential impact of patch heterogeneity at low elevations on regional arctic ground squirrel population dynamics needs to be further explored empirically and theoretically. Furthermore, ground squirrel survival in the forest changes predictably with changes in predator abundance associated with the snowshoe hare cycle (Hubbs and Boonstra 1997, Krebs et al. 2001) and ground squirrels may go through a cycle of source-sink dynamics over time in concert with the snowshoe hare cycle, as suggested by Karels and Boonstra (1999), relying on immigration only during or just after periods of high predation.

Table 3. Robustness of the relative rankings of actual elasticity (AE) coefficients for the boreal forest model to changes in coefficient of variation values $\left(\mathrm{CV}_{\mathrm{i}}\right)$ based on 500 replications in a Monte Carlo simulation. In cases where parameter rankings were equal, all tied perimeters were assigned the highest rank for that value.

\begin{tabular}{lrrrrr}
\hline & \multicolumn{3}{c}{ Relative ranking (\% of simulations) } \\
\cline { 2 - 6 } Parameter & 1st & 2nd & 3rd & 4th & 5 th \\
\hline Adult active season survival $\left(\mathrm{LA}_{\text {act }}\right.$ ) & 62 & 17 & 8 & 6 & 7 \\
Adult winter survival $\left(\mathrm{LA}_{\text {ow }}\right.$ ) & 25 & 36 & 16 & 22 & 0 \\
Reproductive output $(m)$ & 9 & 26 & 33 & 36 & 14 \\
Juvenile winter survival $\left(\mathrm{LJ}_{\text {ow }}\right.$ ) & 0 & 4 & 21 & 25 & 39 \\
Juvenile active season survival $\left(\mathrm{LJ}_{\text {act }}\right)$ & 4 & 16 & 24 & 31 \\
\hline
\end{tabular}




\section{Survival}

Annual female survival was similar in the forest and alpine yet seasonal survival between the two sites differed significantly, with active season survival significantly lower and winter survival significantly higher at the low elevation boreal forest site. These differences were not a result of differences between time spent in hibernation or active between the two sites because females were active at both elevations from late April until late July (McLean and Towns 1981, E. Gillis unpubl.). A previous study also reported similar annual survival rates for adult female arctic ground squirrels living at high and low elevations $(800 \mathrm{~m}$ vs $1525 \mathrm{~m}$, Green 1977).

In our study, female active season mortality, which is most often caused by predators (Hubbs and Boonstra 1997, Byrom et al. 2000), was significantly higher in the boreal forest than the alpine. Predator density was higher at the boreal forest than the alpine site (Hik et al. 2001) and may explain the lower active season survival. Additionally, arctic ground squirrels in the boreal forest may be less able to detect and avoid predators than their alpine counterparts as ground squirrels rely on vision to detect predators at a distance (Balph and Balph 1966, Slade and Balph 1974, Hubbs et al. 1996) and vegetation in the boreal forest may reduce visibility (Karels and Boonstra 1999).

In contrast to active season survival, winter survival was higher in the forest site than in the alpine. Winter mortality occurs during hibernation, and is assumed to result from the physiological demands of hibernation (Green 1977, Karels and Boonstra 2000). In late summer, ground squirrels at the alpine site weighed less than squirrels at the forest site (E. Gillis, unpubl., but see Hik et al. 2001) and may have been in poorer condition, but previous studies on $S$. parryii have found no correlation with mass and winter survival (Green 1977, Karels 2000, but see Michener 1974, Murie and Boag 1984, Slade and Balph 1974 for contrasting results in other Spermophilus spp). The number of suitable hibernacula or specific food resources that reduce the physiological costs of hibernation (Geiser and Kenagy 1993, Karels 2000, Karels et al. 2000) may be more limiting in the tundra than in the boreal forest (Carl 1971, Hubbs and Boonstra 1997, Karels et al. 2000). If so, increased intra- or interspecific competition may be responsible for the difference in overwinter mortality between sites. The alpine site had higher squirrel density, and density dependent winter survival occurs at densities higher than our study (Karels and Boonstra 2000). We found no indication of density dependent winter survival for adult females, but juvenile winter survival was highest in the year with lowest fall density. We could not, however, separate year and density effects. In the alpine, ground squirrels may also compete for resources essential for hibernation with a second hibernating species not found in the forest, hoary marmots (Marmota caligata).

\section{Reproduction}

Contrary to the general trend for vertebrates, including other Spermophilus spp. (Bronson 1979, Zammuto and Millar 1985, Dobson and Murie 1987), arctic ground squirrels at the higher elevation site had greater reproductive output than squirrels at the lower elevation, a result consistent with a study conducted from 1975 to 1977 only $40 \mathrm{~km}$ from our alpine site (Green 1977). Green also reported lower pregnancy and weaning success for arctic ground squirrel females living at lower elevations than at higher elevations, although he detected no difference in mean litter size between high and low elevations.

As in many northern regions, small changes in elevation are associated with changes in habitat (Körner 1999). Habitat may have had more of an effect on reproduction than elevation in our study as habitat differed substantially between sites and may directly affect reproductive output of arctic ground squirrels even at similar elevations (data in Lacey et al. 1997, Karels 2000). Habitat can impact reproduction via sublethal effects acting through physiological or behavioural pathways. Chronic stress in arctic ground squirrels is associated with the increased risk of predation in the boreal forest (Boonstra et al. 1998, Hik et al. 2001). Alternatively, predator sensitive foraging by ground squirrels in the boreal forest may reduce reproductive output during years of high predator density (Karels et al. 2000).

\section{Life history trade-offs}

In general, bird and mammal populations living at higher elevations have lower reproduction but higher female survival than populations of the same species living at lower elevations, indicating a life history tradeoff between survival and reproduction. This apparent life history trade off occurs in at least two species of ground squirrels (S. lateralis, Bronson 1979, S. columbianus, Neuhaus 2000, Neuhaus and Pelletier 2001) but we found no such apparent trade off in arctic ground squirrels in the Kluane region of southwestern Yukon. Similarly, Karels (2000) did not find lower summer or winter survival for arctic ground squirrel females that successfully weaned litters than for non reproductive females when densities were lower than 17 squirrels per hectare.

There is increasing evidence that apparent life history trade offs along elevation gradients are frequently the result of phenotypic plasticity (Bronson 1979, Dobson and Murie 1987, Sorci et al. 1996). Assuming our results 
can be extrapolated beyond our particular sites, the discrepancy between our results and the general trend for mammalian species can be explained as a phenotypic response to environment. Arctic ground squirrels evolved in open arctic tundra habitats (Nadler and Hoffmann 1977), and use a suite of vocal, visual, and behavioural anti-predator tactics effective in areas of high visibility (Balph and Balph 1966, Slade and Balph 1974, Hubbs et al. 1996, Karels and Boonstra 1999). The low elevation boreal forest, with its associated lower visibility, may be sub optimal habitat in which summer survival is reduced because of increased predator abundance and a decreased ability to detect the predators, and reproduction is reduced due sub lethal effects associated with high perceived predation risk. Whether or not the differences are caused by phenotypic plasticity could be tested in the field experimentally transplanting individuals between high and low elevation sites (Sorci et al. 1996).

Acknowledgements - Funding for this study was provided by Natural Sciences and Engineering Research Council (NSERC), Sigma Xi, the Arctic Institute of North America, and NSTP Grants from the Department of Indian and Northern Affairs of Canada. Additional support to E.A.G. was provided by the University of British Columbia University Graduate Fellowship and the Canadian Northern Studies Trust and support to T.J.K was provided the University of Toronto. Many field assistants associated with the Kluane Boreal Forest and Alpine Ecosystem Projects assisted with data collection. We thank R. Ahrens, J. Reid, and B. Wilson for their advice and comments on the manuscript and the Kluane First Nation for their permission to conduct this research on their land.

\section{References}

Badyaev, A. V. and Ghalambor, C. K. 2001. Evolution of life histories along elevational gradients: trade off between parental care and fecundity. - Ecology 82: 2948-2960.

Balph, D. M. and Balph, D. F. 1966. Sound communications of Uinta ground squirrels. - J. Mammal. 46: 440-450.

Bears, H., Smith, J. M. N. and Wingfield, J. C. 2003. Adrenocortical sensitivity to stress in Oregon juncos (Junco hymalis oregonus) breeding in low and high elevation habitat. - Ecoscience 10: 127-133.

Bondrup-Nielsen, S. 1983. Density estimation as a function of live-trapping grid and home range size. - Can. J. Zool. 61: 2361-2365.

Boonstra, R., Hik, D., Singleton, G. R. et al. 1998. The impact of predator-induced stress on the snowshoe hare cycle. - Ecol. Monogr. 79: 371-394.

Boulanger, J. and Krebs, C. J. 1994. Comparison of capturerecapture estimators of snowshoe hare populations. - Can. J. Zool. 72: 1800-1807.

Bronson, M. T. 1979. Altitudinal variation in the life history of the golden-mantled ground squirrel (Spermophilus lateralis). - Ecology 60: 272-279.

Buck, C. L. and Barnes, B. M. 1999. Annual cycle of body composition and hibernation in free-living arctic ground squirrels. - J. Mammal. 80: 430-442.

Byrom, A. E. and Krebs, C. J. 1999. Natal dispersal of juvenile arctic ground squirrels in the boreal forest. - Can. J. Zool. 77: $1048-1059$.

Byrom, A. E., Karels, T. J., Krebs, C. J. et al. 2000. Experimental manipulation of predation and food supply of arctic ground squirrels in the boreal forest. - Can. J. Zool. 78: 1309-1319.

Carl, E. A. 1971. Population control in arctic ground squirrels. - Ecology 52: 395-413.

Caswell, H. 2001. Matrix population models: construction, analysis, and interpretation, second edition. - Sinauer Associates Inc.

Dobson, F. S. and Murie, J. O. 1987. Interpretation of intraspecific life history patterns: evidence from Columbian ground squirrels. - Am. Nat. 129: 382-397.

Dunmire, W. W. 1960. An altitudinal survey of reproduction in Peromyscus maniculatus. - Ecology 41: 174-182.

Ferguson, S. H. and McLoughlin, P. D. 2000. Effect of energy availability, seasonality, and geographic range on brown bear life history. - Ecography 23: 193-200.

Geiser, F. and Kenagy, G. J. 1993. Dietary fats and torpor patterns in hibernating ground squirrels. - Can. J. Zool. 71: $1182-1186$.

Green, J. E. 1977. Population regulation and annual cycles of activity and dispersal in the Arctic ground squirrel. - MSc thesis, Univ. of British Columbia, Vancouver.

Haydon, D. T., Gillis, E. A., Stefan, C. I. et al. 1999. Biases in the estimation of the demographic parameters of a snowshoe hare population. - J. Anim. Ecol. 68: 501512.

Hik, D. S., McColl, C. J. and Boonstra, R. 2001. Why are arctic ground squirrels more stressed in the boreal forest than in alpine meadows? - Ecoscience 8: 275-288.

Hubbs, A. H. and Boonstra, R. 1997. Population limitation in Arctic ground squirrels: effects of food and predation. - J. Anim. Ecol. 66: 527-541.

Hubbs, A. H., Karels, T. and Byrom, A. 1996. Tree-climbing by arctic ground squirrels, Spermophilus parryii, in the southwestern Yukon Territory. - Can. Field Nat. 110: 533-534.

Hood, G. 2002. PopTools version 2.5. CSIRO, Canberra. http:// www.cse.csiro.au/poptools.

Karels, T. J. 2000. Reproduction, hibernation, and population regulation of arctic ground squirrels (Spermophilus parryii plesius ). - $\mathrm{PhD}$ thesis, Univ. of Toronto, Toronto.

Karels, T. J. and Boonstra, R. 1999. The impact of predation on burrow use by Arctic ground squirrels in the boreal forest. - Proc. R. Soc. Lond. B 266: 2117-2123.

Karels, T. J. and Boonstra, R. 2000. Concurrent density dependence and independence in populations of arctic ground squirrels. - Nature 408: 460-463.

Karels, T. J., Byrom, A. E., Boonstra, R. et al. 2000. The interactive effects of food and predators on reproduction and winter survival of arctic ground squirrels. - J. Anim. Ecol. 69: 235-247.

Körner, C. 1999. Alpine plant life: functional plant ecology in high mountain ecosystems. - Springer.

Krebs, C. J. 1999. Ecological methodology, second edition. - Addison-Welsey Educational Publishers, Inc

Krebs, C. J., Boutin, S. and Boonstra, R. 2001. Ecosystem dynamics of the boreal forest. - Oxford Univ. Press.

Kreuzer, M. P. and Huntley, N. J. 2003. Habitat-specific demography: evidence for source-sink population structure in a mammal, the pika. - Oecologia 134: 343-349.

Lacey, E. A. 1991. Reproductive and dispersal strategies of male arctic ground squirrels (Spermophilus parryii plesius). - PhD thesis, Univ. Michigan, Ann Arbor.

Lacey, E. A., Wieczorek, J. R. and Tucker, P. K. 1997. Male mating behaviour and patterns of sperm precedence in arctic ground squirrels. - Anim. Behav. 53: 565-779.

McIntire, E. J. B. and Hik, D. S. 2002. Grazing history versus current grazing: leaf demography and compensatory growth of three alpine plants in response to a native herbivore (Ochotona collaris). - J. Ecol. 90: 348-359.

McLean, I. G. and Towns, A. J. 1981. Differences in weight changes and the annual cycle of male and female arctic ground squirrels. - Arctic 34: 249-254. 
Michener, D. R. 1974. Annual cycle of activity and weight changes in Richardson's ground squirrel, Spermophilus richardsonii. - Can. Field Nat. 88: 409-413.

Millar, J. S. and Innes, D. G. 1985. Breeding by Peromyscus maniculatus over an elevational gradient. - Can. J. Zool. 63: $124-129$.

Murie, J. O. and Boag, D. A. 1984. The relationship of body weight to winter survival in Columbian ground squirrels. - J. Mammal. 65: 688-690.

Nadler, C. F. and Hoffmann, R. S. 1977. Patterns of evolution and migration in the arctic ground squirrel, Spermophilus parryii (Richardson). - Can. J. Zool. 55: 748-758.

Neuhaus, P. 2000. Weight comparisons and litter size manipulation in Columbian ground squirrels (Spermophilus columbians) show evidence of costs of reproduction. - Behav. Ecol. Sociobiol. 48: 75-83.

Neuhaus, P. and Pelletier, N. 2001. Mortality in relation to season, age, sex, and reproduction in Columbian ground squirrels (Spermophilus columbianus). - Can. J. Zool. 79: $465-470$.

Otis, D. L., Burnham, K. P., White, G. C. et al. 1978. Statistical inference for capture data from closed populations. - Wildlife Monogr. 62: 1-135.

Pulliam, H. R. and Danielson, B. J. 1991. Sources, sinks, and habitat selection: a landscape perspective on population dynamics. - Am. Nat. 137: S50-S66.
Rodenhouse, N. L., Sherry, T. W. and Holmes, R. T. 1997. Sitedependent regulation of population size: a new synthesis. - Ecology 78: 2025-2042.

Sall, J., Lehman, A. and Creighton, L. 2001. JMP start statistics: a guide to statistics and data analysis using JMP and JMP IN software. - Duxbury.

Slade, N. A. and Balph, D. F. 1974. Population ecology of Uinta ground squirrels. - Ecology 55: 989-1003.

Sorci, G., Clobert, J. and Belichon, S. 1996. Phenotypic plasticity of growth and survival in the common lizard Lacerta vivipara. - J. Anim. Ecol. 65: 781-790.

Spencer, A. W. and Steinhoff, H. W. 1968. An explanation of geographic variation in litter size. - J. Mammal. 49: $281-$ 286.

Stearns, S. C. 1992. The evolution of life histories. - Oxford Univ. Press.

Sutherland, W. J., Gill, J. A. and Norris, K. 2002. Densitydependent dispersal in animals: concepts, evidence, mechanisms, and consequences. - In: Bullock, M., Kenward, R. E. and Hails, R. S. (eds), Dispersal ecology. Blackwell Science Ltd, pp. 134-151.

Watkinson, A. R. and Sutherland, W. J. 1995. Sources, sinks, and pseudo-sinks. - J. Anim. Ecol. 64: 126-130.

Zammuto, R. M. and Millar, J. S. 1985. Environmental predictability, variability, and Spermophilus columbianus life history over an elevational gradient. - Ecology 66: 1784-1794. 